\title{
Demographic and clinical characteristics of individuals with traumatic spinal cord injury in Argentina from 2015 to 2019: a multicenter study
}

\author{
Marcelo A. Gatti $\mathbb{D}^{1}$ - María P. Sampayo ${ }^{2}$ - Analis Rolandelli ${ }^{3}$ - Santiago Yannone ${ }^{4}$. Fernando J. Argento ${ }^{5}$. \\ María E. Rivas ${ }^{1} \cdot$ María S. Broggi $^{1} \cdot$ Lisandro E. Olmos $^{1} \cdot$ Peter Gorman (i) $^{6}$
}

Received: 24 July 2020 / Revised: 31 October 2020 / Accepted: 8 November 2020

(c) The Author(s), under exclusive licence to International Spinal Cord Society 2020

\begin{abstract}
Study design Descriptive and ambispective study.

Objectives To describe the demographics, clinical characteristics, and etiologies of traumatic spinal cord injury (TSCI) in a metropolitan region of Argentina.

Setting Five inpatient rehabilitation centers in Buenos Aires, Argentina.

Methods We included all patients with acute TSCI who required hospital treatment at five rehabilitation facilities between 2015 and 2019. We collected data using portions of the International Spinal Cord Injury (SCI) Core Data Set.

Results We registered 186 individuals as having TSCI. The males were 77\% of the total sample. The mean age was 36 (SD \pm 15.7 ) years. The distribution between paraplegia and tetraplegia was $50.3 \%$ and $49.7 \%$, respectively. TSCI was complete in $57.3 \%$. Including patients with motor complete SCI, the percentage reached $71.9 \%$ of the sample. Vehicular collisions were the leading cause of TSCI (47.3\%), followed by falls (21.5\%) and assaults (16.1\%).

Conclusions We collected data about demographics, clinical characteristics, and aetiologies of TSCI for the first time in Argentina. The predominant demographic profile of the individuals with TSCI was of young males with complete SCI. We found the most important cause of TSCI was vehicular collisions. Implementation of road safety strategies in this target population might decrease the incidence of TSCI.
\end{abstract}

\section{Introduction}

In Argentina, information related to the causes and demographics of traumatic spinal cord injury (TSCI) is very limited.

Marcelo A. Gatti

marcelogatti@hotmail.com

1 FLENI Rehabilitation Institute, Buenos Aires, Argentina

2 Santa Catalina Neurorehabilitación Clínica, Ciudad Autónoma de Buenos Aires, Argentina

3 Remeo Center, Buenos Aires, Argentina

4 ALPI, Ciudad Autónoma de Buenos Aires, Argentina

5 Instituto de Rehabilitación Psicofísica, Ciudad Autónoma de Buenos Aires, Argentina

6 University of Maryland School of Medicine, Baltimore, MD, USA
TSCI unfortunately is one of the events that most impact a person's life and his or her family. Also, there is a significant increase in healthcare costs generated by the injury both acutely and over the time living with the disability [1-3].

The incidence, rate, and causes of TSCI differ among countries and depend on the period of interest. Globally the TSCI estimated incidence ranges from 10.4 to 83 cases per million per year (Netherlands and Alaska, respectively), with the most frequent incidence being around 15-30 events per million per each year $[4,5]$.

Historically, the main cause of TSCI all around the world is vehicular collision [5-7]. Currently, in several developed countries, the resulting proportion of TSCI due to this cause presents a decreasing number of cases, becoming the second main cause after falls for which incidence steadily increases with the rising age of the general population [5, 8-12]. This change is not observed in developing countries, where TSCIs are mostly caused by vehicular collisions [5]. Therefore, we should elucidate carefully the results 
extracted on the etiology and severity of SCI in developing countries because there might exist discrepancies in the collect data period, the variation of the information compilation, and the presentation of reports $[3,12]$. Due to this, in developing countries that do not report statistics an accurate estimation of patterns about the epidemiology of SCI is not feasible [5, 12].

Like most developing countries, in Argentina to date there are no reliable reports about demographic, clinical, and etiologic characteristics of TSCI [5, 13]. This information is necessary to generate prevention programs for the population with higher risk [12, 14-16].

The general purpose of this study is to describe the demographic, clinical, and etiologic characteristics of TSCI in a metropolitan region of Argentina.

\section{Methods}

Argentina is a South American country with 44 million people. Buenos Aires is the main urban concentration district with 2,890,000 inhabitants.

\section{Design and setting}

A descriptive and ambispective study was developed in patients with TSCI admitted at five of the eight referral rehabilitation centers for SCI in Buenos Aires, between January 1, 2015 and December 31, 2019. Participants were the main public rehabilitation center of Buenos Aires (Instituto de Rehabilitación Psicofisica), and four social security and private facilities (Santa Catalina Neurorehabilitacion, Remeo Center, Alpi, and FLENI).

All consecutive patients aged 16 years or older with TSCI admitted for their first rehabilitation in the centers participating in the research were included in the study. A TSCI case was defined, for this study and similar to Ferro et al. [9], as a hospital admission caused by an acquired traumatic lesion of the spinal cord or cauda equina resulting in a complete or partial, transitory or permanent sensory deficit, motor deficit, bladder or bowel function below the level of the injury [9].

\section{Variables}

A representative of each rehabilitation center was responsible for inputting information on all new TSCI cases received within the study period into a web-based database, created specifically for the investigation. We collected data as follows: gender, age, etiology, completeness, and level of SCI at admission, admission date, and discharge date. We extracted data regarding the International Spinal Cord Injury Core Data Set (ISCICDS) (version 2.0) [17, 18].

\section{Data analysis}

We categorized TSCI's causes into transportation, sports and leisure, assault, fall, and other traumatic causes. The completeness and level of SCI were categorized according to the ISCICDS into five groups: $\mathrm{C} 1-4$ American Spinal Injury Association impairment scale (AIS) A, B, and C; C5-8 AIS A, B, and C; T1-S3 AIS A, B, and C; and AIS D at any injury level. To acquire an adequate sample size for each age grouping to allow satisfactory data analysis, these clinical variables were also grouped by the following categories by age: 16-29, 30-59, and 60+ years old [18].

\section{Statistical analyses}

The continuous variables with normal distribution were disclosed as mean with standard deviation (SD) and those variables with the abnormal distribution were disclosed as median with interquartile range (IQR). We presented categorical variables as frequencies and percentages. The Shapiro-Wilk/Kolmogorov-Smirnov normality test was used in relation to the sample size. The comparison between groups of qualitative variables was carried out with the $\chi^{2}$. We considered a value of $p<0.05$ as significant and we used the statistical package IBM SPSS Statistic, version 23.

\section{Results}

A total of 186 individuals were enrolled with a TSCI or cauda equina injury for their first rehabilitation hospitalization in the five specialized spinal cord injuries (SCIs) centers during the period of 2015-2019.

TSCI incidence for males was superior to females, to be specific $143(77 \%)$ were males and $43(23 \%)$ were females. The average age of the patients was 36 years $(\mathrm{SD}=15.7)$ with a median of 32 years (IQR, 25-47).

Inpatient data admission on the neurological lesion level and AIS classification were obtained in $99 \%$ of cases (Table 1). The distribution between paraplegia and tetraplegia was $50.3 \%$ and $49.7 \%$, respectively. The highest frequency of cases in the age groups occurred in the group

Table 1 Association between lesion level and severity in TSCI cases.

\begin{tabular}{lllcl}
\hline AIS at admission & $\mathrm{C} 1-\mathrm{C} 4$ & $\mathrm{C} 5-\mathrm{C} 8$ & $\mathrm{~T} 1-\mathrm{S} 3$ & Total \\
& $n: 46$ & $n: 34$ & $n: 89$ & $n: 185$ \\
\hline $\mathrm{A}$ & 22 & 16 & 68 & $106(57.3 \%)$ \\
$\mathrm{B}$ & 11 & 9 & 7 & $27(14.6 \%)$ \\
$\mathrm{C}$ & 13 & 9 & 14 & $36(19.5 \%)$ \\
$\mathrm{D}$ & 7 & 5 & 4 & $16(8.6 \%)$ \\
\hline
\end{tabular}

AIS American Spinal Injury Association impairment scale, TSCI traumatic spinal cord injury. 
Table 2 Association between lesion level, severity, and age group in TSCI cases.

\begin{tabular}{lclll}
\hline & \multicolumn{2}{c}{ Age group } & \\
\cline { 2 - 4 } & $16-29$ & $30-59$ & $\geq 60$ & Total \\
\hline $\begin{array}{l}\text { Number of } \\
\text { cases (\%) }\end{array}$ & $81(43.8 \%)$ & $86(46.5 \%)$ & $18(9.7 \%)$ & $185(100 \%)$ \\
Level of injury $^{\mathrm{a}}$ & & & & \\
C1-C4 & $19(10.3 \%)$ & $26(14.1 \%)$ & $8(4.3 \%)$ & $53(28.6 \%)$ \\
C5-C8 & $23(12.4 \%)$ & $11(5.9 \%)$ & $5(2.7 \%)$ & $39(21.1 \%)$ \\
T1-S3 & $39(21.1 \%)$ & $49(26.5 \%)$ & $5(2.7 \%)$ & $93(50.3 \%)$ \\
AIS at admission & & & & \\
A & $53(28.5 \%)$ & $50(26.9 \%)$ & $3(1.6 \%)$ & $106(57.3 \%)$ \\
B & $11(5.9 \%)$ & $13(7.0 \%)$ & $3(1.6 \%)$ & $27(14.6 \%)$ \\
C & $11(5.9 \%)$ & $18(9.7 \%)$ & $7(3.8 \%)$ & $36(19.5 \%)$ \\
D & $6(3.2 \%)$ & $5(2.7 \%)$ & $5(2.7 \%)$ & $16(8.6 \%)$ \\
\hline
\end{tabular}

AIS American Spinal Injury Association impairment scale, TSCI traumatic spinal cord injury.

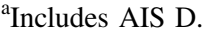

of those aged 30-59 years (46.5\% of cases) (Table 2). Concerning the gravity of the injury, the majority of the individuals $(n: 106 ; 57.3 \%)$ were classified at admission as AIS A (sensorimotor complete injuries). The number of individuals with motor complete SCI (AIS A and B) reached $71.9 \%$ of cases. The prevalence of motor complete SCI was $76.1 \%(n: 127 / 167)$ in individuals $<60$ years old and $33.3 \%(n: 6 / 18)$ in individuals $\geq 60$ years old $(p=0.005)$ (Table 2). Motor complete injuries were more frequent within the thoracic SCI group versus the cervical SCI group (84.3\% versus $72.5 \%$ ) although the difference was not statistically significant (Table 1).

The etiologies of TSCI were recorded for all patients and showed transportation accidents as the first cause (47.3\%) followed by falls $(21.5 \%)$ and assault (16.1\%). In particular, within the cause of transportation accidents, $94.3 \%$ of people were under the age of 60 years old ( $n: 83 / 88)$. Falls were the most frequent cause $(63.1 \%)$ among the population over 60 years of age, both at level and height $(n: 12 / 19)$ (Table 3).

The median length of stay of the 186 patients in the rehabilitation centers was 164 days (IQR, 89-263). The longest hospitalization interval between neurological groups studied was for group C1-C4, AIS B (median 281 days; IQR, 194-324) (Table 4).

\section{Discussion}

Our investigation is the first multicenter epidemiological study of individuals with TSCI developed in Argentina based on the guidelines of the ISCICDS.
Table 3 Specific causes of TSCI by age group.

\begin{tabular}{|c|c|c|c|c|c|c|c|c|}
\hline \multirow{3}{*}{ Etiology } & \multirow{2}{*}{\multicolumn{2}{|c|}{ Total }} & \multicolumn{6}{|c|}{ Age (years) } \\
\hline & & & \multicolumn{2}{|c|}{$16-29$} & \multicolumn{2}{|c|}{$30-59$} & \multicolumn{2}{|c|}{$\geq 60$} \\
\hline & $n$ & $\%$ & $n$ & $\%$ & $n$ & $\%$ & $n$ & $\%$ \\
\hline Transport & 88 & $(47.3)$ & 36 & (19.3) & 47 & $(25.3)$ & 5 & (2.7) \\
\hline Car & 63 & (33.9) & 25 & (13.4) & 34 & (18.3) & 4 & (2.2) \\
\hline Motorcycle & 19 & $(10.2)$ & 11 & (5.9) & 8 & (4.3) & 0 & $(0.0)$ \\
\hline Pedestrian/Bicycle & 6 & $(3.2)$ & 0 & $(0.0)$ & 5 & (2.7) & 1 & $(0.5)$ \\
\hline Fall & 40 & $(21.5)$ & 12 & $(6.5)$ & 16 & (8.6) & 12 & (6.4) \\
\hline From ground level & 8 & $(4.3)$ & 0 & $(0.0)$ & 2 & (1.1) & 6 & (3.2) \\
\hline From height & 32 & $(17.2)$ & 12 & $(6.5)$ & 14 & (7.5) & 6 & (3.2) \\
\hline Sports and Leisure & 25 & (13.5) & 16 & (8.8) & 8 & $(4.2)$ & 1 & $(0.5)$ \\
\hline Sport accident & 12 & $(6.5)$ & 5 & (2.7) & 6 & (3.1) & 1 & $(0.5)$ \\
\hline Diving & 13 & $(7.0)$ & 11 & (5.9) & 2 & (1.1) & 0 & $(0.0)$ \\
\hline Assault & 30 & $(16.1)$ & 16 & (8.6) & 14 & (7.5) & 0 & $(0.0)$ \\
\hline Other traumatic cause & 3 & $(1.5)$ & 1 & $(0.5)$ & 1 & $(0.5)$ & 1 & $(0.5)$ \\
\hline Total & 186 & $(100)$ & 81 & $(43.5)$ & 86 & (46.2) & 19 & $(10.2)$ \\
\hline
\end{tabular}

TSCI traumatic spinal cord injury.

Argentina's health system is pluralistic and it is fragmented into three wide sectors: (1) the public sector which covers people without insurance and represents $\sim 36 \%$ of the population; (2) the social security sector (including Programa de Asistencia Médica Integral, similar to the Medicare Program in the USA) which encompasses to $60 \%$ of the population, and (3) the private sector representing the remaining $4 \%$ of the population. This present study collected data on people with SCI from all three sectors of the Argentina health system. Therefore, it can be considered that the participants are representative of the community of the study region because it combines characteristics of socioeconomic status and heterogeneous ethnic groups [19].

Argentina is included among the $80 \%$ of countries that are considered developing. As of 2013 when the last international review of this topic was published, only 28 countries on that list have presented information regarding the epidemiology of SCI; furthermore, in South America, only Chile and Brazil have researched this topic [12]. The results found by Correa et al. [20] in Chile report the characteristics of persons with TSCI associated with injuries produced in the work environment only. Hence, the characteristics of our sample enabled us only to compare this region with Brazilian data. Brazil is Argentina's biggest neighbor, with five times the population of our country.

The main findings of our research agree with the studies carried out in developing countries and differ from developed countries, strengthening the hypothesis that the studies executed in high-income countries do not apply to developing countries [12]. 
Table 4 Duration of inpatient rehabilitation stay (days).

\begin{tabular}{lllll}
\hline Level of injury & AIS A & AIS B & AIS C & AIS D \\
\hline C1-C4 & $273(145-391)$ & $281(194-324)$ & $189(64-284)$ & $55(36-141)^{\text {a }}$ \\
C5-C8 & $169(88-336)$ & $194(145-365)$ & $212(121-338)$ & \\
T1-S3 & $136(76-200)$ & $173(35-427)$ & $197(90-232)$ & \\
\hline
\end{tabular}

AIS American Spinal Injury Association impairment scale.

${ }^{\mathrm{a}}$ All AIS D, median (IQR).
The average age of patients in our study was 36 years. These results are in accordance with prior epidemiological reports from other similar developing countries, for example, Brazil [21], Nigeria [22], Mexico [23], and Iran [22]. This finding may be explained by the large number of traffic accidents observed in our study as the cause of TSCI among young people [24].

Regarding the severity of the lesion, the majority of patients were assessed as having a complete injury (AIS A). In contrast, many studies accomplished in Western Europe and the USA over the last decades have shown an increasing trend in the number of persons with sensorimotor incomplete injuries $[25,26]$. In our sample, the complete injury was predominant. Even more worrisome in this region of Argentina, SCIs with motor complete SCI occurred in $71.9 \%$ of the registered cases. A more recent study by Barbetta et al. [21] in Brazil found similar results regarding the severity of the lesion, with the prevalence of patients assessed as motor complete SCI at $74.3 \%$.

Another factor to discuss is the causes that produce the SCI. Vehicular collisions (mainly car accidents) were the main cause in the region studied, followed by falls and assaults. da Paz AC et al. on a sample covering 36 public hospitals from seven main Brazilian cities found the prevalent cause of SCI was transit accidents, involving 42\%, comparable to our results (47.3\%) [27]. We believe that Argentina, similar to Brazil, has a railroad-devastated network and thus the roads are the primary means of urban transport—both for passengers and for freight purposes-potentially explaining the higher vehicular accident frequency.

This is in contrast to the most recent literature from developed countries, where an increased incidence is reported for falls that overcome traffic accidents [8$11,15,23]$. This discrepancy might be due to traffic regulations and road safety non-compliance. For example, 2013 data on the utilization of seat belts in Switzerland was reported as $\sim 92 \%$ for front-seat and $72 \%$ for back-seat passengers [11], while in Argentina in a study of 95,782 cars analyzed, only $55 \%$ of drivers and $19 \%$ of the backseat passengers wore seat belts (ANSV 2018) [28].

Falls were the principal cause of SCI among the population over 60 years of age, both at level and height $(63.1 \%)$. We believe that in an aging society, the quantity of fall-induced TSCI would gradually increase due to impairment of balance in this age group. This is similar to the findings from Western European studies as well as in the USA [13].

The length of inpatient rehabilitation stay (median of 164 days, IQR 89-263) was quite long in comparison with current data from other countries for the first period of rehabilitation [8]. The group with high cervical injuries (C1-C4) and motor complete SCI presented the greatest difficulty in returning home. Based on our finding, we believe that the higher proportion of complete TSCI collected in our sample generated the need for many patients to have required equipment (wheelchair, bath chair) and to modify the accessibility to their home for hospital discharge, which constitutes a delay in the return to their homes.

One limitation is that some participants of the populationbased study do not have a permanent address in Buenos Aires. This difficulty is attributable to Argentinian health policies, which do not have designated hospitals for this particular event. Another limitation was that many patients with minor motor and sensory dysfunctions (for example those with AIS D) generally are not being referred to rehabilitation centers and therefore have been left out of our sample, underestimating the general incidence of incomplete SCI.

In conclusion, we collected retrospective and prospective data about demographic, clinical, and etiologic characteristics of TSCI for the first time in Argentina. Based on the findings of the period studied (2015-2019), the most common demographic profile of the individuals with TSCI was of a young male with a complete SCI. The main cause of TSCI in our research was vehicular collision, with $94.3 \%$ being persons under 60 years old. Therefore, the implementation of road safety strategies in this target population might decrease the incidence of TSCI. The long hospital stays found in our study indicate that rehabilitation programs should be improved with the aim of returning patients to their homes earlier. Even though it is difficult to implement a national registry system based on this population, we suggest designing and implementing this type of data collection in health centers that admit persons with SCI to improve future epidemiological studies of this region.

\section{Data availability}

The database sets obtained and analyzed during this study are available from the corresponding author on demand. 
Acknowledgements We express our gratitude to Eliana Buffetti, Jorge Cancino, Leticia Rocco, and Denise Cramer for their assistance in obtaining data records. We thank Maria Julieta Russo for help and guidance.

Author contributions MAG and MPS interpreted the data, developed and wrote the manuscript. MER and LEO gave address statistical and evaluated the manuscript contents. PG made clear suggestions, evaluated in detail the manuscript contents and language revision. AR, MSB, SI, and FA realized data collection and revised manuscript content.

\section{Compliance with ethical standards}

Conflict of interest The authors declare that they have no conflict of interest.

Ethics statement The ethics committee of each participant rehabilitation center approved this study (Number 01-2019).

Publisher's note Springer Nature remains neutral with regard to jurisdictional claims in published maps and institutional affiliations.

\section{References}

1. Thompson C, Mutch J, Parent S, Mac-Thiong J-M. The changing demographics of traumatic spinal cord injury: an 11-year study of 831 patients. J Spinal Cord Med. 2015;38:214-23.

2. Polinder S, Meerding WJ, Mulder S, Petridou E, van Beeck E, EUROCOST Reference Group. Assessing the burden of injury in six European countries. Bull World Health Organ. 2007;85:27-34.

3. Charlifue S, Tate D, Biering-Sorensen F, Burns S, Chen Y, Chun $S$, et al. Harmonization of databases: a step for advancing the knowledge about spinal cord injury. Arch Phys Med Rehabil. 2016;97:1805-18.

4. Wyndaele M, Wyndaele J-J. Incidence, prevalence and epidemiology of spinal cord injury: what learns a worldwide literature survey? Spinal Cord. 2006;44:523-9.

5. Lee BB, Cripps RA, Fitzharris M, Wing PC. The global map for traumatic spinal cord injury epidemiology: update 2011, global incidence rate. Spinal Cord. 2014;52:110-6.

6. Chiu W-T, Lin H-C, Lam C, Chu S-F, Chiang Y-H, Tsai S-H. Review paper: epidemiology of traumatic spinal cord injury: comparisons between developed and developing countries. Asia Pac J Public Health. 2010;22:9-18.

7. Löfvenmark I, Norrbrink C, Nilsson-Wikmar L, Hultling C, Chakandinakira S, Hasselberg M. Traumatic spinal cord injury in Botswana: characteristics, aetiology and mortality. Spinal Cord. 2015;53:150-4

8. Post MWM, Nachtegaal J, van Langeveld SA, van de Graaf M, Faber WX, Roels EH, et al. Progress of the Dutch Spinal Cord Injury Database: completeness of database and profile of patients admitted for inpatient rehabilitation in 2015. Top Spinal Cord Inj Rehabil. 2018;24:141-50.

9. Ferro S, Cecconi L, Bonavita J, Pagliacci MC, Biggeri A, Franceschini M. Incidence of traumatic spinal cord injury in Italy during 2013-2014: a population-based study. Spinal Cord. 2017;55:1103-7.

10. Halvorsen A, Pettersen AL, Nilsen SM, Halle KK, Schaanning EE, Rekand T. Epidemiology of traumatic spinal cord injury in Norway in 2012-2016: a registry-based cross-sectional study. Spinal Cord. 2019;57:331-8.
11. Chamberlain JD, Deriaz O, Hund-Georgiadis M, Meier S, ScheelSailer A, Schubert M, et al. Epidemiology and contemporary risk profile of traumatic spinal cord injury in Switzerland. Inj Epidemiol. 2015;2:28.

12. Rahimi-Movaghar V, Sayyah MK, Akbari H, Khorramirouz R, Rasouli MR, Moradi-Lakeh M, et al. Epidemiology of traumatic spinal cord injury in developing countries: a systematic review. Neuroepidemiology. 2013;41:65-85.

13. Cripps RA, Lee BB, Wing P, Weerts E, Mackay J, Brown D. A global map for traumatic spinal cord injury epidemiology: towards a living data repository for injury prevention. Spinal Cord. 2011;49:493-501.

14. Chen Y, He Y, DeVivo MJ. Changing demographics and injury profile of new traumatic spinal cord injuries in the United States, 1972-2014. Arch Phys Med Rehabil. 2016;97:1610-9.

15. Hagen EM. Still a need for data from developing countries on traumatic spinal cord injury. Neuroepidemiology. 2013;41:86-7.

16. McGrath R, Hall O, Peterson M, DeVivo M, Heinemann A, Kalpakjian C. The association between the etiology of a spinal cord injury and time to mortality in the United States: a 44-year investigation. J Spinal Cord Med. 2019;42:444-52.

17. DeVivo MJ, Biering-Sørensen F, New P, Chen Y, International Spinal Cord Injury Data Set. Standardization of data analysis and reporting of results from the International Spinal Cord Injury Core Data Set. Spinal Cord. 2011;49:596-9.

18. Biering-Sørensen F, DeVivo MJ, Charlifue S, Chen Y, New PW, Noonan $\mathrm{V}$, et al. International Spinal Cord Injury Core Data Set (version 2.0)-including standardization of reporting. Spinal Cord. 2017;55:759-64.

19. Rubinstein A, Zerbino MC, Cejas C, López A. Making universal health care effective in Argentina: a blueprint for reform. Health Syst Reform. 2018;4:203-13. https://doi.org/10.1080/23288604. 2018.1477537.

20. Correa GI, Finkelstein JM, Burnier LA, Danilla SE, Tapia LZ, Torres VN, et al. Work-related traumatic spinal cord lesions in Chile, a 20-year epidemiological analysis. Spinal Cord. 2011;49:196-9.

21. Barbetta DC, Smanioto TR, Poletto MF, Ferreira R, Lopes A, Casaro FM, et al. Spinal cord injury epidemiological profile in the Sarah Network of Rehabilitation Hospitals-a Brazilian population sample. Spinal Cord Ser Cases. 2018;4:32.

22. Obalum DC, Giwa SO, Adekoya-Cole TO, Enweluzo GO. Profile of spinal injuries in Lagos, Nigeria. Spinal Cord. 2009;47:134-7.

23. Zárate-Kalfópulos B, Jiménez-González A, Reyes-Sánchez A, Robles-Ortiz R, Cabrera-Aldana EE, Rosales-Olivarez LM. Demographic and clinical characteristics of patients with spinal cord injury: a single hospital-based study. Spinal Cord. 2016;54:1016-9.

24. Rahimi-Movaghar V, Moradi-Lakeh M, Rasouli MR, Vaccaro AR. Burden of spinal cord injury in Tehran, Iran. Spinal Cord. 2010;48:492-7.

25. BjørnshaveNoe B, Mikkelsen EM, Hansen RM, Thygesen M, Hagen EM. Incidence of traumatic spinal cord injury in Denmark, 1990-2012: a hospital-based study. Spinal Cord. 2015;53:436-40.

26. Devivo MJ. Epidemiology of traumatic spinal cord injury: trends and future implications. Spinal Cord. 2012;50:365-72.

27. da Paz AC, Beraldo PS, Almeida MC, Neves EG, Alves CM, Khan P. Traumatic injury to the spinal cord. Prevalence in Brazilian hospitals. Paraplegia. 1992;30:636-40.

28. Keller MA, Azar J, Naftal C, Benitez RA. Agencia Nacional de Seguridad Vial. 2018. https://www.argentina.gob.ar/sites/default/ files/estudio_de_un_caso_exitoso_en_gestion_de_la_seguridad_ vial._el_uso_de_elementos_de_seguridad_vial_en_mendoza_ version_final.pdf. 